\title{
MARCO REGULATÓRIO DA AGRICULTURA ORGÂNICA: PROTEÇÃO, EFICÁCIA, DIFICULDADES E INTERAÇÕES COM A EDUCAÇÃO AMBIENTAL
}

\author{
Alex Sandro Chagas Mecenas ${ }^{1}$ \\ Jairton Fraga Araújo ${ }^{2}$
}

Resumo: O modelo de desenvolvimento agrícola do Brasil avançou da agricultura de subsistência para uma exploração agroindustrial influenciada pela "revolução verde". Com atenção ao período pós-implantação da Lei 10831/03, regulamentada pelo Dec. 6323/07, esta atividade, experimentou considerável crescimento. Buscou-se compreender a importância dos instrumentos legais do país, sua ligação com a Educação Ambiental e estabelecer o impacto da norma como política pública para a obtenção dos objetivos da lei através da pesquisa bibliográfica e documental. Observou-se que a lei perpassa pela Educação Ambiental e conduziu a agricultura orgânica do Brasil a um patamar de maior desenvolvimento e equivalente aos mais exigentes padrões internacionais.

Palavras-chave: Certificação Orgânica; Lei 10.831/03; Educação Ambiental.

Abstract: Brazil's agricultural development model has moved from subsistence agriculture to an agro-industrial exploitation influenced by the "green revolution". With regard to the period after the implementation of Law 10831/03, regulated by Decree 6323/07, this activity experienced considerable growth. We sought to understand the importance of the country's legal instruments, their connection with environmental education and establish the impact of the norm as a public policy for achieving the objectives of the law through bibliographical and documentary research. It was observed that the law permeates environmental education and led organic agriculture in Brazil to a level of greater development and equivalent to the most demanding international standards.

Keywords: Organic Certification; Law 10.831/03; Environmental Education.

\footnotetext{
1 Universidade do Estado da Bahia. E-mail: ascmecenas@msn.com. Link para o Lattes: http://lattes.cnpq.br/9073496283824010

2 Universidade do Estado da Bahia. E-mail: jafaraujo@uneb.br.

Link para o Lattes: http://lattes.cnpq.br/8734202399025749
} 


\title{
Introdução
}

No século XX a agricultura absorveu o pensamento hegemônico das ciências e entrou numa era de grandes transformações, por meio da conhecida Revolução Verde, o Brasil importou tecnologias de zonas temperadas, sem a devida adequação de sua utilização para as condições ambientais próprias de uma região tropical (BARBOSA et. al, 2011, p. 75). Seguindo os pensamentos do filósofo Francis Bacon, a Revolução Verde orientava-se pela dominação da natureza pelo homem e de uma base tecnológica dependente de adubos químicos, de máquinas e equipamentos agrícolas e agroindustriais, pesquisas genéticas sintéticas em plantas e animais e grande utilização de energia não renovável.

\begin{abstract}
Nesta perspectiva, danos ambientais como a contaminação de mananciais, deterioração dos solos, riscos à saúde de seres humanos e animais) relatados, acentuaram os motivos de preocupação, visto que, entre outros aspectos comprometimento da fertilidade dos solos, estimulou, o consumo de fertilizantes e adubos químicos, gerando, um ciclo vicioso de utilização cada vez maior de insumos potencialmente perigosos ao meio ambiente, que podem acarretar riscos para a saúde da população (VIEITES, 2010, p. 01-12).
\end{abstract}

Nos anos subsequentes e até o momento, a chamada "agricultura convencional", atualmente responsável pela produção da maior parte do cultivo de alimentos e commodities no mundo, passou a enfrentar críticas e questionamentos que remontam ao final do século $\mathrm{XIX}$ e que em consequência, influenciaram o surgimento de práticas e modelos alternativos diversos, visando maior equilíbrio nas intervenções do homem na natureza, conservação e preservação dos recursos naturais e produção de alimentos livres de agrotóxicos, considerados mais saudáveis.

A chamada Agricultura Alternativa, por conseguinte, a Agricultura Orgânica, sua variação mais conhecida, é uma forma de cultivo não convencional, posto neste contexto se contrapondo aos exageros da moderna agricultura industrial, evidentemente esta última, marcada por pacotes tecnológicos que se utilizam de insumos químicos, fertilizantes e técnicas diversas, focando principalmente no aumento da produtividade, e menor preocupação com o meio ambiente e com a manutenção do equilíbrio ecológico.

Portanto, a ideia de uma "agricultura sustentável" revela, antes de tudo, a crescente insatisfação com o "status quo" da agricultura moderna e indica o desejo social de práticas que, simultaneamente, conservem os recursos naturais e forneçam produtos mais saudáveis, sem comprometer os níveis tecnológicos já alcançados de segurança alimentar. Resulta de emergentes 
pressões sociais por uma agricultura que não prejudique o meio ambiente e a saúde (BEZERRA; VEIGA, 2000, p. 10).

Para Dias e Dias (2017, p. 170), a mudança necessária e exigida pela sociedade passa por uma educação voltada para o uso sustentável do meio ambiente e sua preservação, considerando a necessidade de ampliação da produtividade sem provocar dano ambiental, ao mesmo tempo em que possa proporcionar melhoria de vida ao pequeno produtor. Em 1972 a Conferência de Estocolmo já havia feito uma reflexão que é indispensável um trabalho de educação em questões ambientais, dirigida tanto às gerações jovens como aos adultos, para expandir as bases de uma opinião pública bem-informada e propiciar uma conduta dos indivíduos, das empresas e da coletividade, inspirada no sentido da responsabilidade quanto a proteção e melhoria do meio ambiente em todas as dimensões humanas.

A busca de formas alternativas de produção agrícola tem sido acompanhada por controvérsias. Para alguns, agricultura orgânica é ficção de naturalistas inconsequentes; para outros ela é uma revolução, por exemplo, a Revolução Verde (MAZZOLENI; NOGUEIRA, 2006, p. 263-293).

Desse modo, o fato concreto é que em nome de uma melhor qualidade de vida, as pessoas estão mudando seus hábitos alimentares e consequentemente buscando alimentos considerados mais saudáveis, onde se incluem os produtos denominados "orgânicos", ou seja, produtos produzidos através do sistema orgânico (LIMA et al., 2011, p. 68).

Assim, essa realidade, constituída a partir da conscientização dos problemas ambientais e dos riscos que eles causam à manutenção da vida humana, fez com que as pessoas passassem a se preocupar não só com a saúde ambiental, mas com sua própria saúde (LYRIO et al., 2011, p. 48), esse comprometimento, promoveu um amplo desenvolvimento da agricultura orgânica, acontecendo de forma muito intensa em várias regiões do mundo, principalmente na União Europeia.

Dados da FiBL e IFOAM (2018, p. 22) afirmam que em 2016, havia 57,8 milhões de hectares de terras com agricultura orgânica, incluindo áreas de conversão. Oceania (27,3 milhões de hectares, quase metade da terra agrícola orgânica do mundo) e Europa (13,5 milhões de hectares, 23\%). A América Latina com 7,1 milhões de hectares (12 por cento), seguida pela Ásia $(4,9$ milhões de hectares, 9 por cento), América do Norte (3,1 milhões de hectares, 6 por cento) e África (1,8 milhões de hectares, 3 por cento). Os países com mais áreas destinadas a produção orgânica são a Austrália (27,4 milhões de hectares), a Argentina (3 milhões de hectares) e a China (2,3 milhões de hectares). 
Neste importante cenário mundial, o Brasil vem aumentando a sua área de produção com agricultura orgânica, onde a criação de uma lei específica para o setor trouxe avanços e conquistas importantes tanto para produtores e consumidores; mas há uma ligação com processos de interações e Educação Ambiental? qual a sua real eficácia, proteção, dificuldades?

\section{Metodologia}

Para a obtenção do objetivo proposto deste estudo, o artigo foi desenvolvido sob a ótica da pesquisa exploratória, já que segundo Gil (2007, p. 43), este tipo de pesquisa tem como visam apresentar um problema, enfatizando-o ou formulando hipóteses. Para Zikmund (2000, p.34),

a pesquisa exploratória é geralmente útil para diagnosticar situações, explorar alternativas ou descobrir novas ideias. Este trabalho é realizado na fase inicial de um processo de pesquisa mais amplo, que visa esclarecer e definir a natureza do problema e gerar mais informações que possam ser adquiridas para a realização de futuras pesquisas conclusivas.

Quanto à coleta de dados, foram empregados procedimentos de pesquisa bibliográfica e documental, com revisão teórica dos assuntos que tratam da temática da agricultura orgânica e correlatos, na qual se buscou fontes importantes e dados históricos e estatísticos coerentes com as movimentações mercadológicas avistadas e elegendo como principais fontes os periódicos científicos mais atualizados, bem como sites e órgãos especializados a fim de se obter maior relevância nos resultados.

Vergara (2000, p. 46-48) define que a pesquisa bibliográfica é desenvolvida a partir de material já desenvolvido, constituído, principalmente, de livros e artigos científicos e é importante para o levantamento de informações básicas sobre os aspectos direta e indiretamente ligados à nossa temática. A principal vantagem da pesquisa bibliográfica baseia-se no fato de fornecer ao investigador um instrumental analítico para qualquer outro tipo de pesquisa, mas também pode esgotar-se em si mesma.

Da mesma forma, Marconi e Lakatos (2003, p. 76-77) afirmam que que a pesquisa bibliográfica não pode ser conceituada como uma mera repetição do que já foi dito ou escritos sobre determinado assunto, mas propicia o exame de um tema sob um novo enfoque ou abordagem, chegando assim a conclusões inovadoras.

Já a pesquisa documental, segundo Gil (1999, p. 51), é muito semelhante à pesquisa bibliográfica. 
A diferença essencial entre ambas está na natureza das fontes: enquanto a bibliográfica se utiliza fundamentalmente das contribuições de diversos autores, a documental vale-se de materiais que não receberam, ainda, um tratamento analítico, podendo ser reelaboradas de acordo com os objetos da pesquisa.

Além de apresentá-los e discuti-los, foram analisados os três diferentes modelos de acreditação orgânica brasileiros, onde as informações levantadas foram objeto de apresentação em figuras e tabelas de modo a possibilitar uma melhor compreensão dos dados comparativos e norteadores do panorama da agricultura orgânica no Brasil.

\section{Resultados e Discussão}

\section{Lei no 10.831/03, o marco regulatório da agricultura orgânica no Brasil: proteção, eficácia e dificuldades}

Ente os dispositivos legais para regulação de produção orgânica destaca-se a Lei dos Orgânicos (lei 10.831/03) como principal marco legal da agricultura orgânica brasileira, estabelecendo critérios para comercialização de produtos e definindo responsabilidades pela qualidade orgânica, bem como procedimentos relativos à fiscalização, à aplicação de sanções, registro de insumos e adoção de medidas sanitárias e fitossanitárias que não comprometam a qualidade orgânica dos produtos.

Em seu primeiro artigo: estabelece:

Art. 1 "Considera-se sistema orgânico de produção agropecuária todo aquele em que se adotam técnicas específicas, mediante a otimização do uso dos recursos naturais e socioeconômicos disponíveis e o respeito à integridade cultural das comunidades rurais, tendo por objetivo a sustentabilidade econômica e ecológica, a maximização dos benefícios sociais, a minimização da dependência de energia não-renovável, empregando, sempre que possível, métodos culturais, biológicos e mecânicos, em contraposição ao uso de materiais sintéticos, a eliminação, a utilização ae organısmos geneticamente modificados e radiação ionizante em qualquer etapa do processo produtivo, processamento, armazenamento, distribuição e comercialização, e a proteção do meio ambiente".

Para Aquino e Assis (2007, p. 137-150), essa (re)interpretação do que seja a agricultura orgânica, com foco prioritário no chamado "mercado orgânico" favoreceu a criação de sistemas produtivos tidos como orgânicos, baseados em tecnologias de produtos. Mazzoleni e Nogueira (2006, p. 263- 
293) acrescentam ainda que a agricultura orgânica, do ponto de vista governamental, é uma oportunidade de formulação de políticas públicas e que o potencial brasileiro para a agricultura orgânica são os agricultores familiares excluídos da agricultura química.

Além da importância da lei 10.831/03, a legislação Brasileira para produtos orgânicos possui ainda um arcabouço importante de portarias e instruções normativas. O histórico das normas e da legislação para os produtos orgânicos no Brasil começou com a Portaria MA n.178, agosto 1994 Comissão Especial para propor normas e certificação de produtos orgânicos que culmina com a Instrução Normativa MA n. 007, maio 1999 - trata da produção, processamento, acondicionamento e transporte de produtos orgânicos. Abrange os produtos orgânicos, ecológicos, biodinâmicos, naturais, sustentáveis, regenerativos, biológicos, agroecológicos e da permacultura (FONSECA, 2002, p.267-297). Mas de forma mais abrangente, não nos esqueçamos da Lei 9.795/99, denominada lei do meio ambiente e Educação Ambiental, que a médio e longo prazo formará um leque maior de produtores e consumidores mais conscientes e preocupado com alimentos produzidos com tecnologias limpas e em consonância com a preservação ambiental.

O artigo $1^{\circ}$ da lei 9.795/99 explana que se entende por Educação Ambiental os processos por meio dos quais o indivíduo e a coletividade constroem valores sociais, conhecimentos, habilidades, atitudes e competências voltadas para a conservação do meio ambiente, bem de uso comum do povo, essencial à sadia qualidade de vida e sua sustentabilidade. Doutrinariamente podemos definir a Educação Ambiental como "o processo educacional de estudos e aprendizagem dos problemas ambientais e suas interligações com o homem na busca de soluções que visem a preservação do meio ambiente (SANTOS, $1999 \mathrm{p}$ 101).

Após as normas postas em vigor na década de 90 e a lei 10.831 em 2003, houve uma intensificação nos normativos pelo MAPA, com especial atenção ao Decreto 6.323/07 e às Instruções Normativas 54/08, 64/08, 17/09, 18/09, 19/09, 50/09 e 01/11.

Estados Unidos e Europa há anos possuem legislações específicas que normatizam a produção, beneficiamento e a comercialização. Na América do Sul, a Argentina é o país mais avançado em termos de produção e regulamentação dos produtos orgânicos. De acordo com Willer e Yussef (2006, p. 166-167), no início desse processo no Brasil, a normalização era estabelecida pelas próprias associações e organizações de agricultores, organizações não governamentais (ONGs), cooperativas de consumidores e técnicos das áreas agrícolas, considerando as normas internacionais estabelecidas pelo setor privado nos países desenvolvidos. Willer e Yussef (2006, p. 167) explicam ainda que a necessidade da regulamentação para os orgânicos acontece com 0 natural distanciamento entre agricultores e consumidores quando do crescimento do mercado. 
A Lei 10.831, é o principal marco legal da agricultura orgânica brasileira, estabelecendo critérios para comercialização de produtos, definindo quanto à responsabilidade pela qualidade orgânica, quanto aos procedimentos relativos à fiscalização, aplicação de sanções, registro de insumos e adoção de medidas sanitárias que não comprometam a qualidade orgânica dos produtos (SAMINÊZZ et al., 2008, p. 2).

\section{Proteção da Lei 10.831/2003}

Em um breve relato histórico, Fonseca (2002, p.267-297), preconiza que a necessidade da regulamentação para os orgânicos acontece com 0 natural distanciamento entre agricultores e consumidores quando do crescimento do mercado. No início desse processo no Brasil, a normalização era estabelecida pelas próprias associações e organizações de agricultores, ongs, cooperativas de consumidores e técnicos das áreas agrícolas, considerando as normas internacionais estabelecidas pelo setor privado nos países desenvolvidos, como as da IFOAM. Quando começaram as tentativas de exportação (cacau e açúcar) para Alemanha nos anos de 1988/89, efetivadas em 1990, as certificadoras europeias passaram a exercer pressão para o reconhecimento de uma certificadora brasileira. No ano de 1992, aumentou a pressão em face da promulgação pela União Europeia da UE 2092/91, que trata da comercialização de alimentos orgânicos nos seus países membros.

Para Fonseca (2007, p. 60), o crescimento do mercado de consumo de produtos orgânicos gerou a necessidade de se criar normas jurídicas para permitir uma concorrência saudável e leal entre os fornecedores (produtores primários, processadores, comerciantes, supermercados, restaurantes etc.), bem como para garantir a proteção da saúde e segurança do consumidor através do acompanhamento da qualidade. A certificação de produtos orgânicos constitui-se em uma série de procedimentos estabelecidos e acordados entre agricultores, compradores de produtos agrícolas, comerciantes e consumidores que garantem esses bens ou serviços foram produzidos de forma diferenciada dos demais. No caso dos produtos orgânicos, a certificação dá ao consumidor a garantia de que eles foram produzidos de forma orgânica.

Para entender a necessidade de certificação orgânica, é importante distinguir entre três tipos de produtos: i) bens sob demanda, ii) bens de experiência e iii) bens de fé. Para fins analíticos, o primeiro grupo (bens sob demanda) oferece todas as informações relevantes para a transação antes da troca. Para produtos experimentais, alguns dados - como textura, sabor e critérios de saúde - só podem ser obtidos após a troca ou após o consumo. No terceiro grupo (bens de crença), algumas informações relevantes não são obtidas nem após o consumo (BATALHA; SILVA, 2001, p. 30).

Nesse último grupo estão inseridos os orgânicos, visto que um consumidor de uma grande cidade, por exemplo, observando apenas 0 
produto, não poderá identificar se o alimento que vai comprar, comprar ou mesmo consumir, foi produzido em um sistema orgânico que respeita o meio ambiente. Esse tipo de produto necessita de certificação ou algum outro tipo de acreditação (MAZZOLENI; OLIVEIRA, 2010, p. 570-582). O processo de regularização da produção orgânica em nosso país obedece a um regramento próprio expresso na Lei 10.831/2003, que em conjunto com suas resoluções posteriores compõem o Sistema Brasileiro de Avaliação da Conformidade Orgânica (SisOrg).

No Brasil, são reconhecidos três mecanismos de garantia: a certificação por auditoria, que utiliza uma terceira parte isenta e de credibilidade entre produtores, comerciantes e consumidores, que estabelece a garantia de que os produtos respeitaram procedimentos orgânicos até chegarem ao consumidor final; os sistemas participativos de garantia (SPG), que fazem parte do Sistema Brasileiro de Avaliação da Conformidade Orgânica (SisOrg) e são sistemas sócio participativos de organização com controle social, normalmente em forma de rede, de abrangência regional de atuação, com o envolvimento e participação de todos que formam a rede; e o controle social para a venda direta sem certificação. Desta forma, a agricultura orgânica está contemplada com modelos diferentes e variados de garantia das qualidades a serem colocados à disposição dos consumidores, o que por certo, se revela em um grande benefício para o desenvolvimento social atrelado ao setor.

Certificação por auditoria é a avaliação da conformidade orgânica pela qual a garantia da qualidade orgânica do produto, obtida em determinada unidade de produção, é dada por uma terceira parte, não envolvida no processo produtivo, a certificadora, que é uma instituição que inspeciona as condições técnicas, sociais e ambientais e verifica se estão de acordo com os regulamentos técnicos específicos da produção orgânica (BRASIL, 2007). A certificação é concretizada com a assinatura de contrato entre certificadora e representante legal da unidade de produção, com consequente autorização para utilização da marca da certificadora (SAMINÊZ et al., 2008, p. 5). Esse tipo de certificação é um processo caro que geralmente só pode ser bancado por grandes produtores ou então por grupos de produtores através de associações ou cooperativas (OLIVEIRA et al., 2013, p. 14-27).

Segundo dados do Ministério da Agricultura, Pecuária e Abastecimento, existem vários organismos de certificação (certificadoras) atuando no País e a função principal, é a de garantir aos consumidores através da rotulagem com o selo (marca de qualidade) na embalagem, que o produto foi elaborado segundo as normas da produção orgânica estabelecidas na legislação brasileira. Destas, há um maior número de certificações do Instituto Biodinâmico (IBD) e da ECOCERT Brasil Certificadora. Apesar de baseado em critérios internacional de coleta de dados, procedimento, avaliações e acreditação de propriedades, produtos e processos, cada certificadora possui o seu protocolo e fluxo específico de emissão de certificação e auditoria.

O Sistema Participativo de Garantia - SPG, de acordo com o Decreto 
avaliação da conformidade. Sendo considerados membros do sistema: os produtores, comercializadores, transportadores, armazenadores, consumidores, técnicos e organizações públicas ou privadas que atuam na rede de produção orgânica.

O conjunto de atividades desenvolvidas no sistema tem como base o controle social, a participação e responsabilidade compartilhada para estabelecer mecanismos razoáveis de responsabilidade e garantia dos processos desenvolvidos por seus membros. O SPG também é caracterizado por decisões descentralizadas e compartilhamento de conhecimento (SAMINÊZ et al., 2008, p. 5).

No caso da comercialização direta aos consumidores, por parte dos agricultores familiares, inseridos em processos próprios de organização e controle sociais, previamente cadastrados junto ao órgão fiscalizador, a certificação será opcional, após a rastreabilidade do produto ter sido garantida aos consumidores e à autoridade supervisora ou processamento (BRASIL, 2003). Localmente a legislação brasileira abriu uma exceção na obrigatoriedade de certificação dos produtos orgânicos para a agricultura familiar.

Para que o agricultor familiar possa comercializar diretamente ao consumidor seus produtos como orgânicos é necessário cumprir os regulamentos técnicos da produção orgânica, e sua organização de controle social (OCS) deverá se cadastrar em órgão fiscalizador (MAPA) ou o órgão fiscalizador emitirá declaração de cadastro para cada membro da OCS. Assim o produtor familiar poderá se identificar como orgânico através da apresentação de seu cadastro, e o rótulo de seus produtos e os locais de comercialização poderão conter a expressão "produto orgânico" para venda direta por agricultores familiares organizados não sujeito à certificação de acordo com a Lei 10.831, de 23 de dezembro de 2003" (SAMINÊZ et al., 2008, p. 4).

Afirma ainda que os sistemas participativos de garantia e o controle social para a venda sem certificação usa os mecanismos da organização com controle social para avaliação, garantia e informação da qualidade orgânica. Radomsky (2009, p. 133-164), expõe que com a implementação da certificação participativa e por credibilidade compartilhada no âmbito da Rede, conseguiu envolver diversos atores sociais individuais e coletivos, permitiu a organização de eventos e feiras consecutivas, estimulou novos hábitos de consumo - ainda que sobre um pequeno percentual da população - e de controle sobre a produção agrícola. Além disso, o autor ainda afirma que incentivou 0 pensamento crítico sobre as práticas de certificação, gerando um sentimento de que são possíveis outras maneiras de verificação e controle da produção agroecológica, que sejam socialmente construídas. 
Devido ao fato de que os agroecológicos possuiriam uma condição em que uma pessoa comum dificilmente os distingue de um produto convencional, eles se tornaram selos que confirmam sua autenticidade (RADOMSKY, 2009, p. 133-164). Segundo RADOMSKY (2009, p. 164) é quase evidente que todo bem tem uma face de "crença" num certo sentido, pois antes de experimentá-lo - consumidor "crê" que ele possa satisfazer seus desejos. Porém, na agricultura ecológica a situação é mais minuciosa, uma vez que produtos convencionais e ecológicos colocados lado a lado são, em alguns casos, difíceis de serem distinguidos, e até mesmo o sabor e a contextura interna podem ser semelhantes.

Advindas como uma resposta a este "problema", as certificações de todo tipo entram no cenário como mecanismos de verificação e comprovação, a certificação impõe imperativos tanto para um comércio de longa como para o de curta distância aplicando qualificativos essenciais aos produtos RADOMSKY (2009 p. 161). De acordo com a International Organization for StandardizationISO (2019), a certificação significa a emissão escrita da garantia - o certificado - por uma empresa externa e independente: a certificadora. Esta empresa audita o sistema administrativo e de verificação da empresa que deseja o certificado.

A obtenção da certificação orgânica para os produtores rurais que seguem as normas e procedimentos impostos pelas certificadoras e pela legislação específica concede aos mesmos um status de bons produtos e boas propriedades aos seus possuidores. Já para o consumidor fornece a garantia de obtenção de um produto realmente livre de adubos sintéticos, agrotóxicos e organismos geneticamente modificados entre outros aspectos de exclusão.

A legislação preconiza ainda que o Sistema Brasileiro de Avaliação da Conformidade Orgânica (SISOrg) será identificado por selo único em todo o território nacional. O selo do SISOrg (Figura 1), estará presente em todos os produtos orgânicos em que avaliação da conformidade tenha sido realizada por OAC (OPAC) credenciado no MAPA (BRASIL, 2007). A identificação do mecanismo de avaliação de conformidade aplicado será adicionada ao selo. Hoje existem diversos organismos de certificação (certificadoras) atuando no País e a função principal, é a de garantir aos consumidores através de rotulagem com o selo (marca de qualidade) desde a embalagem, de que o produto foi elaborado segundo as normas da produção orgânica estabelecidas na legislação brasileira.

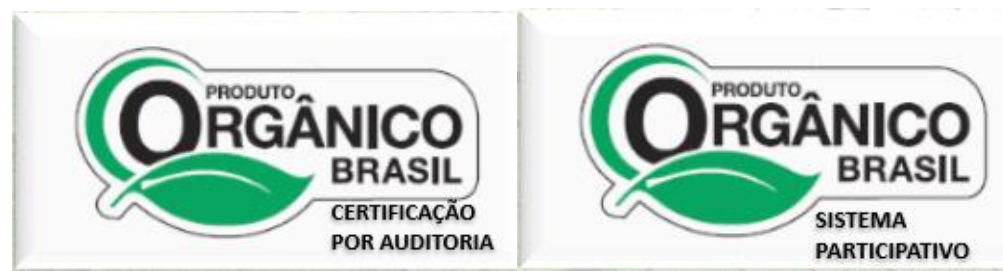

Figura 1: Logomarca do MAPA para produto orgânico no Brasil. Fonte: Ministério da Agricultura, Pecuária e Abastecimento - MAPA. 
Eficácia: reflexos positivos após a implantação da Lei 10. 831/2003

Para Chiechelski (2005, p. 4-6), a eficácia é utilizada como critério para avaliar o alcance dos objetivos e metas das políticas ou programas, representando uma medida de aproximação ou distanciamento entre os objetivos/metas previstos e os resultados efetivamente praticados. Existem os seguintes tipos de eficácia: a espontânea que, está relacionada ao reconhecimento e a vivência, resultado da adoção racional das leis pelos seus destinos; a compulsória que são as normas que contrariam as tendências numa comunidade e os tribunais não recusam a aplicação às leis que estiverem em vigor e; a nula quando esta deixa de ser utilizada.

Seguramente, a promulgação da legislação de orgânicos brasileira, além de assegurar o direito dos consumidores e de chancelar os produtores e propriedades orgânicas, norteou a produção, beneficiamento e comercialização desses tipos de produtos no território nacional. Apesar de o Brasil ter demorado em aprovar a sua lei de agricultura orgânica se comparada com a União Europeia, Estados Unidos, Japão e a vizinha Argentina, a lei brasileira possui dispositivos bastantes avançados oriundos de normas internacionais e outros que agrega elementos sociais de confiabilidade e fiscalização mútua entre os produtores rurais. As normas internacionais traduzidas principalmente sobre a forma de certificação através de empresas e organizações certificadoras internacionais, a chamada certificação por auditoria, e em menor grau com os OPAC, permitiram a produção, beneficiamento e a exportação de diversos produtos para vários países do mundo, conforme mostra a Tabela 1.

Tabela 1: Destino das exportações brasileiras de produtos orgânicos - ago/2006 a jan/2010 (Após a promulgação da Lei da Agricultura Orgânica - Lei 10.831/2003).

\begin{tabular}{lccc}
\hline $\begin{array}{l}\text { País de } \\
\text { Destino }\end{array}$ & $\begin{array}{c}\text { Quant. Exportada } \\
(\mathbf{K g})\end{array}$ & Valor (US\$) & Participação (\%) \\
\hline Holanda & 13.894 .587 & 9.569 .347 & 29 \\
Suécia & 8.640 .420 & 6.276 .148 & 19 \\
\hline Estados Unidos & 6.820 .199 & 4.081 .042 & 12,4 \\
Reino Unido & 3.188 .250 & 2.625 .439 & 8 \\
França & 4.298 .350 & 2.445 .608 & 7,4 \\
Bélgica & 1.669 .640 & 1.692 .166 & 5,1 \\
Canadá & 473.212 & 1.467 .459 & 4,5 \\
Noruega & 1.283 .622 & 1.262 .878 & 3,8 \\
Japão & 472.565 & 853.500 & 2,6 \\
Dinamarca & 1.600 .629 & 810.522 & 2,5 \\
Alemanha & 1.562 .000 & 757.390 & 2,3 \\
Itália & 252.000 & 198.102 & 0,6 \\
\hline Outros & 1.268 .048 & 913.120 & 2,6 \\
TOTAL & $\mathbf{4 5 . 4 2 3 . 5 2 2}$ & $\mathbf{3 2 . 9 6 2 . 7 5 3}$ & $\mathbf{1 0 0 , 0}$ \\
\hline
\end{tabular}

Fonte: MDIC/SECEX (2010). Obtida de MADAIL, BELARMINO e BINI, 2011.

A flexibilização estabelecida pela lei permitiu reflexos positivos ao autorizar que os agricultores também possam ter acesso à certificação, principalmente através de grupos de produtores. Nesse sentido, o incentivo a organização dos produtores em associações ou cooperativas é um ponto importante para permitir uma maior participação da agricultura familiar na 
produção orgânica nacional (OLIVEIRA et al., 2013, p. 14-27). Os sistemas participativos de garantia e o controle social para a venda direta sem a certificação utiliza os mecanismos de uma organização com controle social para avaliação, garantias e informações da qualidade orgânica.

Para Saminêz et al. (2008, p. 7), o produtor ao colocar no mercado um produto com selo orgânico, pode obter vantagens em relação ao produto convencional, pois cada vez mais o consumidor tende a dar a um produto cuja qualidade inclui características relacionadas à saúde, justiça social e proteção e preservação ambiental, que é o caso do produto orgânico, especialmente quando há preços competitivos. Outra vantagem para o produtor, citada pelo autor, é o aumento da preferência pela aquisição do produto orgânico pelos mercados institucionais, como por exemplo, as escolas, os hospitais e o Programa de Aquisição de Alimentos - PAA da Companhia Nacional de Abastecimento - CONAB, onde o produto orgânico sobrevaloriza cerca de $30 \%$ em relação ao convencional. Outro dado importante que comprova a eficácia da lei dos orgânicos, e que é demonstrado na Tabela 2, é o crescente aumento do número de certificações, seja esta através de uma certificadora ou por meio dos mecanismos de controle do Ministério da Agricultura, Pecuária e Abastecimento.

Tabela 2: Comparativo do Número de Produtores Orgânicos segundo UF e Mecanismo de

\begin{tabular}{|c|c|c|c|c|c|c|c|c|}
\hline \multicolumn{9}{|c|}{ Controle (2015 e 2017). } \\
\hline & \multicolumn{4}{|c|}{2015} & \multicolumn{4}{|c|}{2017} \\
\hline & & \multicolumn{3}{|c|}{ Mecanismos de Controle } & \multicolumn{4}{|c|}{ Mecanismos de Controle } \\
\hline UF & OPAC & OCS & CERT & Produtor & OPAC & OCS & CERT & Produtor \\
\hline $\mathrm{AC}$ & 0 & 32 & 1 & 33 & 0 & 32 & 213 & 245 \\
\hline AL & 0 & 29 & 5 & 34 & 0 & 95 & 14 & 109 \\
\hline AM & 0 & 14 & 49 & 63 & 0 & 128 & 70 & 198 \\
\hline AP & 0 & 0 & 1 & 1 & 0 & 0 & 90 & 90 \\
\hline BA & 0 & 69 & 311 & 380 & 0 & 90 & 285 & 375 \\
\hline $\mathrm{CE}$ & 122 & 0 & 343 & 465 & 124 & 0 & 730 & 854 \\
\hline DF & 20 & 64 & 26 & 110 & 89 & 80 & 47 & 216 \\
\hline ES & 0 & 43 & 113 & 156 & 1 & 155 & 151 & 307 \\
\hline GO & 0 & 29 & 66 & 95 & 11 & 41 & 49 & 101 \\
\hline MA & 0 & 0 & 308 & 308 & 0 & 0 & 287 & 287 \\
\hline MG & 75 & 83 & 252 & 410 & 195 & 100 & 228 & 523 \\
\hline MS & 1 & 23 & 151 & 175 & 9 & 15 & 128 & 152 \\
\hline MT & 0 & 115 & 67 & 182 & 0 & 113 & 71 & 184 \\
\hline PA & 0 & 18 & 179 & 197 & 0 & 85 & 598 & 683 \\
\hline PB & 0 & 262 & 86 & 348 & 0 & 352 & 106 & 458 \\
\hline PE & 69 & 587 & 42 & 698 & 76 & 579 & 80 & 735 \\
\hline $\mathrm{PI}$ & 21 & 124 & 914 & 1059 & 23 & 135 & 852 & 1010 \\
\hline PR & 741 & 48 & 492 & 1281 & 1144 & 137 & 918 & 2199 \\
\hline RJ & 243 & 94 & 37 & 374 & 369 & 66 & 37 & 472 \\
\hline RN & 29 & 308 & 88 & 425 & 33 & 426 & 51 & 510 \\
\hline RO & 0 & 85 & 22 & 107 & 0 & 97 & 33 & 130 \\
\hline $\mathrm{RR}$ & 0 & 10 & 0 & 10 & 0 & 37 & 0 & 37 \\
\hline RS & 691 & 362 & 183 & 1236 & 766 & 342 & 762 & 1870 \\
\hline SC & 867 & 0 & 192 & 1059 & 678 & 0 & 486 & 1164 \\
\hline SE & 0 & 262 & 10 & 272 & 0 & 264 & 9 & 273 \\
\hline SP & 136 & 430 & & 1216 & 159 & & 706 & 1672 \\
\hline TO & \multicolumn{4}{|c|}{ Não consta } & \multicolumn{4}{|c|}{ Não consta } \\
\hline 3RASII & 3015 & 3091 & 4588 & 10694 & 3677 & 4176 & 7001 & 14854 \\
\hline
\end{tabular}

Legenda: OPAC - Organismos Participativos de Avaliação da Conformidade, OCS - organização de controle social, CERT - Certificação por auditoria.

Fonte: LEMES et. al. (2018). 
Segundo Lemes et. al. (2018, p. 181-196), o Cadastro Nacional de Produtores Orgânicos do MAPA (2017), revelou que o Brasil possui 14.854 produtores orgânicos e nos últimos anos observou-se um aumento acentuado destes produtores. Por exemplo, de 2015 a 2017 houve um aumento de 39,6\% no total de produtores orgânicos. Esta expansão tem sido mais acentuada nos estados da região sul, destacando-se o Paraná, cujo crescimento absoluto foi de 918 produtores orgânicos (equivalente a $71,6 \%$ no período).

A Lei 10.831, de 23 de dezembro de 2003 promoveu a agricultura orgânica do Brasil a um patamar mais elevado e equivalente aos mais exigentes padrões internacionais. Permitiu ao consumidor brasileiro que outrora possuía apenas a palavra do produtor e/ou vendedor do produto obter garantia na compra do alimento. Na visão de Terrazzan e Valarini (2009, p. 27-41), um dos fatores fundamentais para a ampliação da produção e comercialização de orgânicos é o processo de certificação, tendo grande importância estratégica para o mercado de orgânicos, pois além de permitir ao agricultor diferenciar seu produto, melhor lucro, protege os consumidores de possíveis fraudes, reduzindo a forte assimetria de informação entre vendedores e consumidores, dificultando a adoção de práticas oportunistas.

Em termos gerais, o advento da lei dos orgânicos, e posteriormente a implementação da lei $n^{\circ} 11.947$, de 16 de junho de 2009, regulamentada pela resolução $n^{\circ} 38$ do conselho deliberativo do Fundo Nacional de Desenvolvimento da Educação (FNDE), vislumbrou um novo caminho para a expansão do sistema orgânico de produção, bem como do mercado, em todos os municípios brasileiros, visto que esta determina que no mínimo $30 \%$ dos recursos do FNDE, repassados no âmbito do Programa Nacional de Alimentação Escolar (PNAE), sejam aplicados na compra diretamente dos agricultores familiares e que se deve dar preferência aos alimentos orgânicos e/ou agroecológicos (BARBOSA; SOUSA, 2012, p. 67-74).

A promulgação da lei dos orgânicos possibilitou mais fortemente a Inserção dos pequenos agricultores nas redes nacionais e internacionais de comercialização de produtos orgânicos, fato que outrora só era possível através da certificação por auditoria e com um volume maior de produto, já que grande parte da comercialização era feita de forma individual.

\section{Dificuldades apresentadas pelo marco regulatório}

Apesar dos imensos avanços oriundos da referida lei, a legislação traz consigo algumas dificuldades e problemas que devem ser encarados pela sociedade e governo na busca de soluções conjuntas e viáveis para sua efetiva e irrestrita consolidação. Comparado ao universo de agricultores no Brasil, o percentual que pratica a certificação em sua produção é muito baixa, o que prejudica a comercialização, já que a certificação prevê a transparência ao consumidor (BARBOSA; SOUSA, 2012, p. 73).

De acordo com a pesquisa realizada por Barbosa e Souza (2012, p. $72-$ 
73), entre as principais dificuldades enfrentadas pelos produtores desse segmento, destacam-se o baixo nível escolaridade dos agricultores, acesso limitado à assistência técnica e participação reduzida em organizações sociais. Essas deficiências influenciam a baixa adoção de certificação por parte dos produtores orgânicos, de forma que a melhoria dessas variáveis pode contribuir para a expansão do uso da certificação, mas sem esquecer que o custa da certificação reflete no aumento do preço do produto orgânico ao consumidor final, que segundo Sousa et al. (2012, p. 515), pode variar de 20 até $100 \%$ mais para os produtos orgânicos em relação aos de origem convencional. Além disso, a comercialização e as exigências do mercado são, normalmente, as maiores dificuldades individuais para 0 ingresso na produção orgânica (MAZZOLENI; OLIVEIRA, 2010, p. 567-586).

Padovan (2016, p. 133) menciona que outro fator que interfere negativamente nas unidades produtivas é a burocracia exigida para a certificação inerente à gestão da propriedade e da produção, uma vez que há necessidade de preenchimento de vários formulários, e vários agricultores possuem baixa escolaridade, levando-os à desmotivação. Já para Muñoz et al. (2016, p. 361-376), o tempo de certificação é o problema, pois varia entre um e dois anos, sendo necessário um processo de aprendizagem que, segundo o produtor, tem sido rigoroso, pois além de produzir de uma forma diferente, os produtores têm tido que assimilar diversas informações das normativas que devem ser cumpridas, as quais, segundo o produtor, caracterizam-se por apresentam burocracia e complicações para pequenos produtores, exigindo registros detalhados em caso de uma produção familiar.

Apesar da adoção e importância da Lei 9.795/99 que disciplina a Educação Ambiental em espaços formais e não formais de educação, a baixa escolaridade dos agricultores é limitante para o real entendimento da legislação e da obrigatoriedade de utilizar técnicas, manejo e preparados nesse tipo de cultivo e de mercado. Barbosa e Souza (2012, p. 74) utilizando dados do IBGE de 2009 que preconizam que o nível de instrução predominante entre os produtores orgânicos é o ensino fundamental incompleto, seguido pelos que não sabem ler e escrever, juntas, as duas categorias representam $63,9 \%$ dos produtores. Em termos de certificação, os dados apresentados na Figura 2 revelam que $6,1 \%$ dos produtores com ensino fundamental incompleto certificam sua produção orgânica por meio de entidade credenciada, enquanto apenas $1,6 \%$ dos produtores que não sabem ler e escrever adotam essa prática, em contrapartida, $4,7 \%$ dos produtores orgânicos possuem ensino superior, dos quais $11,6 \%$ fazem uso da certificação. 


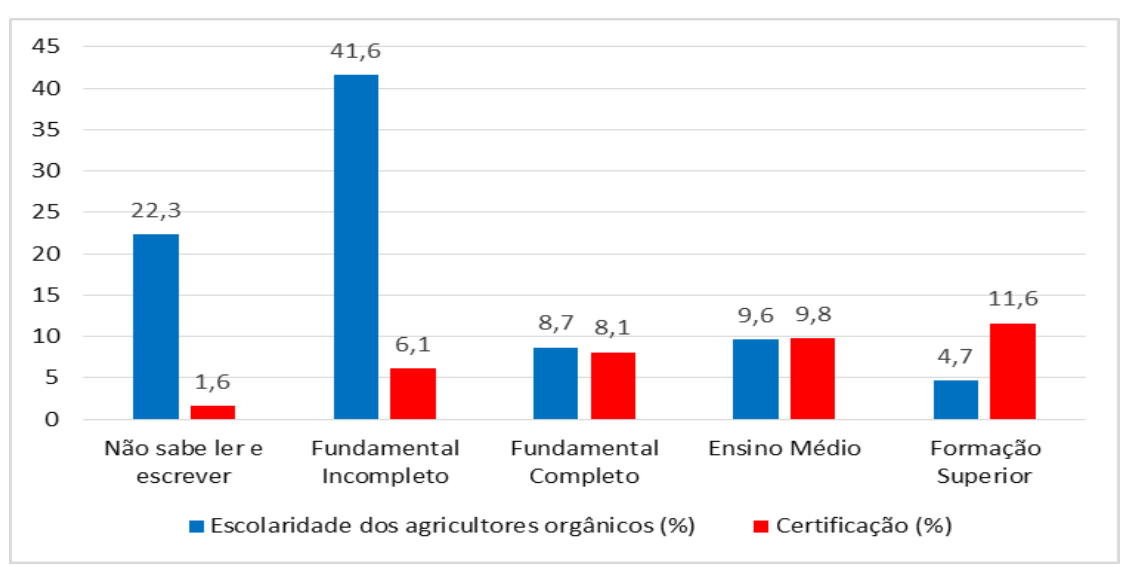

Figura 2: Relação entre escolaridade do agricultor e certificação da produção orgânica e propriedade. Fonte: Adaptada de Barbosa e Sousa (2012).

Ainda sobre a égide da necessidade de aumento da escolaridade e de preparação para o desenvolvimento da atividade agrícola orgânica, Mazzoleni e Nogueira (2006, p. 567-586), afirmam que é condição básica, o agricultor ser devidamente capacitado. Conhecer os princípios da agricultura orgânica, os objetivos da visão da propriedade como um organismo, a integração da agricultura e da pecuária para fertilização do solo, a importância da biodiversidade, práticas de conservação ecológica e todos os outros conhecimentos para crescer com eficiência técnica e econômica. A relação escolaridade e este segmento do setor econômico e social é visibilizada pela dificuldade de obtenção de dados mais atuais que correlacionem a limitação da atividade produtiva e pouca escolaridade daqueles que a desenvolvem. Para Queiroz et al. (2019, p. 289-306), a Educação Ambiental é a principal resposta para o desenvolvimento da agricultura orgânica no seio da agricultura familiar. $\mathrm{O}$ apoio técnico qualificado e a capacitação dos atuais e futuros agricultores aliados ao financiamento são as perspectivas de desenvolvimento para grande parte da população rural brasileira.

A ausência ou ineficiência de assistência técnica permanente é um entrave na agricultura familiar, sendo ela orgânica, agroecológica ou convencional. Apesar da Política Nacional de Assistência Técnica e Extensão Rural para a Agricultura Familiar e Reforma Agrária - PNATER, promulgada pela Lei no 12.188, de 11 de janeiro de 2010, priorizar a agroecologia como princípio basilar e definir Assistência Técnica e Extensão Rural - ATER como serviço de educação não formal, de caráter continuado, no meio rural, que promove processos de gestão, produção, beneficiamento e comercialização de atividades e serviços agrícolas e não agrícolas, incluindo atividades agroextrativas, florestais e artesanais, na prática observa-se uma grande ausência da assistência técnica devido a diversos motivos que perpassam pela formação convencional dos técnicos, ausência de política agrícola efetiva com princípios orgânicos, ausência de recursos financeiros, entre outros. Na visão de Mazzoleni e Oliveira (2010, p. 570-571), um dos gargalos reside na 
escassez de profissionais que consigam responder a todas as exigências da cadeia produtiva orgânica, desde os conceitos mais básicos de sustentabilidade até o domínio da legislação que regula a produção orgânica no Brasil.

A inserção de novas tecnologias sociais, assistência técnica, apoio à comercialização e oferta de crédito são essenciais para melhorar a eficiência da produção e viabilizar a sustentabilidade econômica das atividades produtivas, pois o apoio de organizações públicas e privadas reduz a fragilidade inicial e os riscos associados ao mercado (WILKINSON, 2008, p. 216). Apesar do avanço da legislação orgânica em conceder aos agricultores familiares uma forma diferenciada de certificação de seu produto através do Sistema Participativo de Garantia (SPG), essa permissão é extremamente limitada por permitir apenas a comercialização direta.

Como comercialização direta o decreto $n^{\circ}$ 6.323, de 27 de dezembro de 2007 que regulamenta a Lei № 10.831, de 23 de dezembro de 2003 define a ação como relação comercial direta entre o produtor e o consumidor final, sem intermediários ou preposto, desde que seja o produtor ou membro da sua família inserido no processo de produção e que faça parte da sua própria estrutura organizacional (BRASIL, 2007).

Sendo assim, a venda direta não pode ser aplicada à indústria, porque ela transforma o bem no processo de produção para gerar um novo bem que vai ser vendido, ou seja, ela não consome o produto. Por parte do Governo Federal observa-se que nos últimos anos houve certo enfraquecimento dos acompanhamentos e fiscalizações do MAPA in loco nos grupos e propriedades participantes do Sistema Participativo de Garantia (SPG). Isso possivelmente pela diminuição dos recursos financeiros nas instituições públicas ou quem sabe até uma forma de observação e autorregulação natural do setor. O fato é que ausência ou diminuição de acompanhamento em um sistema onde o seu pilar fundamental é a confiança, não parece ser uma boa estratégia de atuação governamental, dando margem a possíveis desvios de condutas de seus integrantes.

De acordo com Lourenço et al. (2017, p. 45-46), os dados do Censo Agropecuário de 2006 evidenciam que neste ano, dentre total de 5.175.636 estabelecimentos agropecuários no Brasil, havia 90.498 que utilizavam a produção orgânica, representando $1,75 \%$ do total dos estabelecimentos. No entanto, os dados obtidos no site do MAPA indicam que atualmente há 17.856 estabelecimentos credenciados para a prática da agricultura orgânica no Brasil. Esta diminuição pode ter sido motivada pela simples regulação do mercado, que já exclui aqueles que não possuem intenção de regularizar-se, mas também pelos motivos já expostos.

De acordo com Dos Santos et. al, (2012, p. 35-41), o crescimento da 
agricultura orgânica poderia ainda ser maior, haja vista que existe uma grande demanda por esses produtos, mas, infelizmente, apesar da expansão da oferta, ela ainda é insuficiente. Estudos recentes na área apontam que o mercado de orgânicos está se consolidando, mas que a produção não acompanha a demanda. Há uma carência de produção, o que contribui para manter os produtos orgânicos em um nicho de mercado muito limitado, com preços inacessíveis para a maioria da população (CONSTANTY et al., 2013).

Para tanto, a agricultura orgânica precisa disputar o mercado real, sem ficar apenas na expectativa de que basta produzir bens sem resíduos químicos e de melhor qualidade, utilizando sistemas e processos que respeitam o meio ambiente. Assim, necessita atingir maior lucratividade para ser competitiva e sobreviver no atual mercado (MAZZOLENI; OLIVEIRA, 2010, p. 567-586). O fato é que se de um lado a agricultura orgânica obteve grandes avanços a partir da lei 10.831/2003, de outro, ainda precisa trilhar um longo caminho para diminuição ou resolução das dificuldades apresentadas após a promulgação deste marco regulatório.

\section{Conclusões}

Apesar de haver decorrido muitos anos para sua implementação, o marco regulatório brasileiro, que está dentro de uma estratégia maior de desenvolvimento sustentável que agrega outros princípios de sustentabilidade e outras legislações que perpassam pela conscientização educacional de todos os atores do processo, trouxe consigo elementos conceituais avançados, como a possibilidade de fiscalização pelos próprios beneficiários, bem como inclusão social e produtiva de agricultores. Apesar de haver críticas em cada mecanismo de certificação da produção, beneficiamento e comercialização de produtos orgânicos, a legislação se apresenta como um meio democrático de fornecimento destes produtos, onde a escolha de cada certificação é definida pelo agricultor em função da sua estrutura produtiva, dos seus recursos financeiros e principalmente pelo mercado que deseja comercializar. Com a observação do setor e a revisão bibliográfica, conclui-se que se para o agricultor a lei 10.831/2003 trouxe parâmetros de segurança na produção através de normas a serem seguidas e amplitude mercadológica com a possibilidade de inserção dos produtos em mercado institucional e outros mais exigentes, para os consumidores propiciou proteção e garantia para aquisição dos produtos orgânicos desejados, já que orienta este elo da cadeia comercial e dificulta a realização de inconformidades e práticas em desacordo com a legislação. Apesar da eficácia alcançada pela lei na maioria dos seus objetivos, sua completa efetivação e ampliação precisa superar as dificuldades que ainda impedem uma maior adesão de agricultores à produção orgânica, bem como agregar-se nas ações e políticas de Educação Ambiental que devem apoiar e nortear o setor e ampliar ainda mais a base produtiva e consumidores, afinal, a agricultura orgânica e a Educação Ambiental se confundem em alguns aspectos e têm como marco inicial os princípios da sustentabilidade, no sentido 
de preservar o meio ambiente, e com isto promovem também a qualidade de vida, defendendo e garantindo às futuras gerações o princípio basilar de preservar e proteger os recursos naturais.

\section{Referências}

AQUINO, A. M.; ASSIS, R.L. Agricultura Orgânica em áreas urbanas e periurbanas com base na agroecologia. Rev. Ambiente \& Sociedade. Campinas, v.X, n.1, 2007. p. 137-150.

BARBOSA, S. C.; MATTEUCCI, M. B. A.; LEANDRO, W. M.; LEITE, A. F.; CAVALCANTE, E. L. S.; ALMEIDA, G. Q. E. Perfil do consumidor e oscilações de preços de produtos agroecológicos. Revista Pesquisa Agropecuária Tropical (PAT). Goiânia, v. 41, n. 4, out./dez. 2011. p. 71-95.

BARBOSA, W. F.; SOUSA, E. P. Agricultura Orgânica no Brasil: características e desafios. Revista Economia \& Tecnologia (RET). V. 8, № 4, 2012. p. 67-74.

BATALHA, M. O.; SILVA. A.L. Gerenciamento de sistemas agroindustriais: definições e correntes metodológicas. In.: Batalha, M. O. (Coor.) Gestão agroindustrial: GEPAl; São Paulo: Atlas, 2001. p. 23-63.

BEZERRA, M.C.L.; VEIGA, J.E. Agricultura Sustentável. Brasília: Ministério do Meio Ambiente; Instituto Brasileiro do Meio Ambiente e dos Recursos Naturais Renováveis; Consórcio Museu Emílio Goeldi, 2000. p. 10- 13.

BRASIL. Lei $n^{\circ}$ 9.795, de 27 de abril de 1999, que dispõe sobre a Educação Ambiental, institui a Política Nacional de Educação Ambiental e dá outras providências. Disponível em: $<$ http://www.planalto.gov.br/ccivil 03/leis/19795.htm> Acesso em 11 de junho, 2021.

BRASIL. Decreto no 6.323, de 27 de dez. 2007. Regulamenta a Lei no 10.831, de 23 de dezembro de 2003, que dispõe sobre a agricultura orgânica e dá outras providências. Diário Oficial [da] República Federativa do Brasil, Brasília, DF, 28 de dez. 2007.

BRASIL. Lei no 10.831, de 23 de dez. 2003. Dispõe sobre a agricultura orgânica e dá outras providências. Diário Oficial da República Federativa do Brasil, Brasília, DF, 24 de dez. 2003.

CHIECHELSKI, P. C. S. Avaliação de programas sociais: abordagens quantitativas e suas limitações. Revista Virtual Textos \& Contextos, n. 4, ano IV. 2005. p 4-6. Disponível em: http://revistaseletronicas.pucrs.br. Acesso em: 29 maio 2016.

CONSTANTY, H. F. P.; TOILLIER, S. L.; HERRMANN, D. R.; WENGRAT, A. P. G. S. GARCIA, R. C. O programa paranaense de certificação de produtos orgânicos: experiências passadas e atuais na região Oeste do Paraná. Resumos do VIII Cong. Brasileiro de Agroecologia/ Porto Alegre/RS, 2013. 
DECLARAÇÃO DA CONFERÊNCIA DAS NAÇÕES UNIDAS SOBRE O MEIO AMBIENTE HUMANO. XXI Reunião Plenária do Secretariado-Geral, em 16 de junho de 1972 . Disponível em: <https://brasil.un.org/ptbr/resources/publications $>$. Acesso em 10 de junho, 2021.

DIAS, M. A. de O.; DIAS, A. A. S. Educação Ambiental: A agricultura como modo de sustentabilidade para a pequena propriedade rural. Revista de Direitos Difusos. v. 68 - Julho-Dezembro/2017.

DOS SANTOS, J. O.; SANTOS, R. M. S.; BORGES, M. G. B.; FERREIRA, R. T. F. V.; SALGADO, A. B. A evolução da agricultura orgânica. Revista Brasileira de Gestão Ambiental (RBGA). Pombal - PB, v.6, n.1, p. 35 - 41, janeiro/dezembro de 2012.

FONSECA, M. A. C. Desafios e perspectivas dos sistemas participativos de garantia. Rev. Bras. de Agroecologia, vol. 2, n. 2, out. 2007. p. 60.

FONSECA, M. F. Certificação de sistemas de produção e processamento de produtos orgânicos de origem animal: história e perspectivas. Cadernos de Ciência \& Tecnologia. Brasília, v.19, n.2, 2002. p.267-297.

FORSCHUNGSINSTITUT FUR BIOLOGISCHEN LANDBAU - RESEARCH INSTITUTE OF ORGANIC AGRICULTURE, SWITZERLAND - FIBL; INTERNATIONAL FEDERATION OF ORGANIC AGRICULTURE MOVEMENTS - IFOAM. The world of organic agriculture - Statistics \& emerging trends 2018. Disponível em: <https://shop.fibl.org/CHde/mwdownloads/download/link/id/1093/?ref=1>.

Acesso em: 10 jan. 2019.

GIL, A. C. Métodos e técnicas de pesquisa social. 6. ed. São Paulo: Atlas, 2009. p. 51.

GIL, A. C. Como elaborar projetos de pesquisa. 4 ed. São Paulo: Atlas, 2007. $\mathrm{p} 43$.

INTERNATIONAL ORGANIZATION FOR STANDARDIZATION - ISO. Certification, registration and accreditation. Disponível em: $<$ https://www.iso.org/files/live/sites/isoorg/files/archive/pdf/en/publicizing iso900 1 iso14001 certification 2010.pdf> Acesso em 10 de janeiro de 2019.

MARCONI, M. A.; LAKATOS, E. M. Fundamentos de metodologia científica. 5.ed. São Paulo: Atlas, 2003. p. 75-82.

MAZZOLENI, E. M.; OLIVEIRA, L.G. Inovação tecnológica na Agricultura Orgânica: estudo de caso da certificação do processamento pós-colheita. RESR, Piracicaba, SP, vol. 48, oㅡ 03, Impresso em outubro 2010. p. 567-586.

LEMES, C. D.; OIKAWA, I.; MICHELLON, E. Panorama dos mercados de produtos orgânicos mundial, brasileiro e paranaense. Revista GeoPantanal, UFMS/AGB, Corumbá/MS, n. 24,.. jan./jun. 2018. p. 181-196. 
LIMA. P. A. L.; BRUNINI, M. A.; KANESIRO, L. A.; KANESIRO, J. C.; MACIEL JÚNIOR, V. A.; COLOMBO, R. B. Perfil do consumidor de produtos orgânicos na cidade de São Joaquim da Barra / SP. Nucleus, v.8, n.1, 2011.

LYRIO, E.S. et.al. Recursos Vegetais em Biocosméticos: Conceito Inovador de Beleza, Saúde e Sustentabilidade. Natureza Online, v.9, n.1, pp.47-51, 2011.

LOURENÇO, A. V.; SCHNEIDER, S.; GAZOLLA, M. A agricultura orgânica no brasil: um perfil a partir do censo agropecuário 2006. Extensão Rural, DEAER - CCR - UFSM, Santa Maria, v.24, n.1, jan./mar. 2017. p. 45-46.

MADAIL, J. C. M.; BELARMINO, L. C.; BINI, D. A. Evolução da produção e mercado de produtos orgânicos no Brasil e no mundo. Revista Científica da Ajes, Juína, 3 ed., 2011.

MAZZOLENI, E. M.; NOGUEIRA, J.M. Agricultura orgânica: características básicas do seu produtor. RER, Rio de Janeiro, vol. 44, nº 02, - Impressa em junho 2006. p. 263-293.

MAZZOLENI, E. M.; OLIVEIRA, L.G. Inovação tecnológica na Agricultura Orgânica: estudo de caso da certificação do processamento pós-colheita. RESR, Piracicaba, SP, vol. 48, № 03, impressa em outubro 2010.

MUÑOZ, C. M. G.; GÓMEZ, M. G. S.; SOARES, J. P. G.; JUNQUEIRA, A. M. R. Normativa de Produção Orgânica no Brasil: a percepção dos agricultores familiares do assentamento da Chapadinha, Sobradinho (DF). RESR, Piracicaba-SP, Vol. 54, № 02. 2016. - Impressa em Junho 2016. p. 361-376.

NOGUEIRA, V. M. R. Avaliação e monitoramento de políticas e programas sociais - revendo conceitos básicos. Revista Katálysis, Florianópolis, v. 5, n. 2, jul./dez. 2002. p. 141-152.

OLIVEIRA, M. A. C.; SAMBUICHI, R. H. R.; SILVA, A. P. M. Experiências agroecológicas brasileiras: uma análise à luz do desenvolvimento local. Rev. Bras. de Agroecologia, 2013. p. 14-27.

PADOVAN, D. S. S. Avanços e desafios no processo de certificação da produção orgânica no estado de Mato Grosso do Sul. Dissertação (Mestrado em Agronegócios) - Faculdade de Administração, Ciências Contábeis e Economia, Universidade Federal da Grande Dourados, 2016. p. 133.

QUEIROZ, I.N.L.F.; MEDEIROS-SILVEIRA, I.M.; GARCIA-RÊGO, A.H., FALCÃO-FREIRE, A.L.B.; MOREIRA, S. A. Educação para a produção agrícola sustentável: agricultura orgânica versus agroecologia na percepção de estudantes da Escola Agrícola em Jundiaí (RN). Revista Brasileira de Educação Ambiental, 14(3), 2019. p. 289-396.

RADOMSKY, G. F. W. Práticas de certificação participativa na agricultura ecológica: rede, selos e processos de inovação. Rev. Interfaces em Desenvolvimento, Agricultura e Sociedade IDeAS, v. 3, n. 1, 2009. p. 133-164.

SAMINÊZ, T. C. O.; DIAS, R. P.; NOBRE, F. G. A.; MATTAR, R. G. H.; GONÇALVES, J. R. A. Legislação e os Mecanismos de Controle e informação 
da Qualidade Orgânica no Brasil. Embrapa Hortaliças: Circular Técnica. Brasília, DF, 2008.

SANTOS A. S. R. dos. Base legal da Educação Ambiental no Brasil: programa Ambiental: a Ultima Arca de Noé, 1999.

SCHUEROFF, M. L. G.; PEREIRA, J. A. Efetividade e eficácia do programa bolsa família no município de Alto Paraná-PR. Anais do II Encontro Internacional de Gestão, Desenvolvimento e Inovação. Naviraí, MS, 2018. p. 8.

SOUSA, A. A.; AZEVEDO, E.; LIMA, E. E.; SILVA, A. P. F. Alimentos orgânicos e saúde humana: estudo sobre as controvérsias. Rev Panam Salud Publica. 2012. p. 513-517.

TERRAZZAN, P; VALARINI, P. J. Situação do Mercado de Produtos Orgânicos e as Formas de comercialização no Brasil. Informações Econômicas, SP, v.39, n.11, nov. 2009. p. 27-41.

VERGARA, SYLVIA C. Projetos e relatórios de pesquisa em administração. 3.ed. Rio de Janeiro: Atlas, 2000.

VIETES, R. G. Agricultura Sustentável: uma alternativa ao modelo convencional. Revista Geografar, Curitiba, v.5, n.2, p.01-12, jul./dez. 2010.

WILKINSON, J. Mercados, Redes e Valores. Porto Alegre: UFRGS, 2008. p. 216.

WILLER, H.; YUSSEFI, M. The World of Organic Agriculture: Statistics and Emerging Trends 2006. p. 166-167.

ZIKMUND, W. G. Business research methods. 5.ed. Fort Worth, TX: Dryden, 2000. 